\title{
International Consensus Guidance for Management of Myasthenia Gravis
}

\section{Update}

Pushpa Narayanaswami, MBBS, DM, Donald B. Sanders, MD, Gil Wolfe, MD, Michael Benatar, MD, Gabriel Cea, MD, Amelia Evoli, MD, Nils Erik Gilhus, MD, Isabel Illa, MD, Nancy L. Kuntz, MD, Janice Massey, MD, Arthur Melms, MD, Hiroyuki Murai, MD, Michael Nicolle, MD, Jacqueline Palace, MD, David Richman, MD, and Jan Verschuuren, MD

Neurology ${ }^{\circledR}$ 2021;96:114-122. doi:10.1212/WNL.0000000000011124

\section{Abstract}

\section{Objective}

To update the 2016 formal consensus-based guidance for the management of myasthenia gravis (MG) based on the latest evidence in the literature.

\section{Methods}

In October 2013, the Myasthenia Gravis Foundation of America appointed a Task Force to develop treatment guidance for $\mathrm{MG}$, and a panel of 15 international experts was convened. The RAND/UCLA appropriateness method was used to develop consensus recommendations pertaining to 7 treatment topics. In February 2019, the international panel was reconvened with the addition of one member to represent South America. All previous recommendations were reviewed for currency, and new consensus recommendations were developed on topics that required inclusion or updates based on the recent literature. Up to 3 rounds of anonymous e-mail votes were used to reach consensus, with modifications to recommendations between rounds based on the panel input. A simple majority vote ( $80 \%$ of panel members voting "yes") was used to approve minor changes in grammar and syntax to improve clarity.

\section{Results}

The previous recommendations for thymectomy were updated. New recommendations were developed for the use of rituximab, eculizumab, and methotrexate as well as for the following topics: early immunosuppression in ocular MG and MG associated with immune checkpoint inhibitor treatment.

\section{Conclusion}

This updated formal consensus guidance of international MG experts, based on new evidence, provides recommendations to clinicians caring for patients with MG worldwide.
Correspondence Dr. Narayanaswami pnarayan@ bidmc.harvard.edu 


\section{Glossary}

$\mathbf{A C h R}=$ acetylcholine receptor; $\mathbf{A C h R}-\mathbf{A b}+=\mathrm{AChR}$-positive; $\mathbf{C O I}=$ conflicts of interest $\mathbf{C S R}=$ complete stable remission; CTLA-4 = cytotoxic T-lymphocyte-associated protein 4; ICP = immune checkpoint; irAE = immune-related adverse event; IS = immunosuppressive; IVIg = intravenous immunoglobulin; MG = myasthenia gravis; MG-ADL = MG-activity of daily living; $\mathbf{M G C}=$ MG-composite; MGFA = Myasthenia Gravis Foundation of America; $\mathbf{M M}=$ minimal manifestation; $\mathbf{M M T}=$ Manual Muscle testing; MTX = methotrexate; MuSK = muscle specific kinase; OLE = open-label extension; PD-1 = programmed cell death protein 1; PDL-1 = programmed cell death ligand 1; PIS = postintervention status; $\mathbf{Q M G}=$ quantitative MG; RCT = randomized controlled trial; REGAIN = refractory generalized nonthymomatous AChR-Ab+ MG; RTX = rituximab.

Evidence-based recommendations for the treatment of myasthenia gravis (MG) have historically been difficult to develop because of limited evidence from studies with a low risk of bias such as large, well-designed randomized controlled trial studies (RCTs). To address the lack of uniform, globally accepted standards for the care of people with MG, the Myasthenia Gravis Foundation of America (MGFA) appointed a Task Force in 2013 to develop treatment recommendations for MG. A panel of 15 international experts in the treatment of MG was convened and, in 2016, published an international consensus guidance for the management of MG. ${ }^{1}$

Results of several new trials of MG treatment have been published since that guidance statement was published, and in 2019, the panel reviewed the previous recommendations for currency and identified new topics that may affect practice. All members of the previous MGFA Task Force participated in this update; one new member (G.C.) was added to the international panel, which now consists of experts from Canada (M.N.), Chile (G.C.), Germany (A.M.), Italy (A.E.), Japan (H.M.), Norway (N.E.G.), the Netherlands (J.V.), Spain (I.I.), UK (J.P.), and USA (P.N., D.S., G.W., M.B., N.K., J.M.M., and D.P.R.). All except P.N. were voting members; P.N. served as the methodologist.

\section{Methods}

Topics informing new recommendations were selected based on a review of studies of the treatment of $M G$ published since 2013. Panel members disclosed any conflicts of interest (COI) using the Neurology COI disclosure form; all conflicts were reviewed by the panel co-chairs (D.S. and G.W.). One or two panel members prepared narrative reviews of the recent literature and proposed initial recommendations for each topic. Conflicted panel members abstained from participating in the literature review and from developing initial recommendation statements for the conflicted topic(s) but participated in the group discussions and voting to obtain expert consensus for all topics.

\section{Topics Identified for the Development of Recommendations}

Based on the availability of new clinical trial data that the panel co-chairs determined may affect previous recommendations or lend themselves to new recommendations, the following interventions were selected: thymectomy, rituximab (RTX) in MG with antibodies to acetylcholine receptors (AChRs) and muscle-specific kinase (MuSK), eculizumab, and methotrexate (MTX). Recommendations were also developed to inform early immunosuppression in ocular MG, the role of physical training/exercise in MG, and the management of $M G$ associated with immune checkpoint inhibitor treatment. Physical training/exercise was excluded after review because of the low quality of evidence informing recommendations.

The RAND/UCLA appropriateness method for formal consensus was used to obtain consensus, with the same a priori assumptions regarding treatment availability and costs as in the initial guidance document. ${ }^{1,2}$ All voting was conducted by e-mail and the responses returned only to the methodologist to avoid the potential for panel members' opinions and votes being influenced by others. Topics were voted on sequentially, although rounds of voting for different topics frequently overlapped for efficiency. All recommendation statements were edited after the first round of voting by the co-chairs and methodologist in response to the panel's suggestions for changes and depending on whether consensus was reached or not. The edited recommendations were sent by e-mail to the panel along with collated panel comments from the previous round for voting. The process was repeated for up to 3 rounds of voting, as needed. Recommendations that did not achieve consensus after 3 rounds of voting were discarded. The panel rated each recommendation for appropriateness on a 9-point scale (1-3: inappropriate, 4-6: uncertain, and 7-9: appropriate). Median and range were calculated for each recommendation to assess appropriateness and agreement per the RAM method. Tables e1-e10, doi:10.5061/dryad.6hdr7sqxx, summarize all the recommendations of the original guideline that are still current plus those from the present update. Table 1 provides an update of drugs to avoid or use with caution in MG.

\section{Results}

All recommendations below achieved panel consensus agreement as being appropriate, and these recommendations should be considered extensions or additions to recommendations made in the initial international consensus guidance. ${ }^{1}$ 
Table 1 Drugs to Avoid or Use With Caution in $\mathrm{MG}^{\mathrm{a}}$

\begin{tabular}{ll}
\hline Drug & Comment \\
\hline $\begin{array}{l}\text { Aminoglycoside antibiotics (e.g., gentamycin, neomycin, and } \\
\text { tobramycin) }\end{array}$ & $\begin{array}{l}\text { Used for gram-negative bacterial infections. May worsen MG. Use cautiously } \\
\text { if no alternative treatment available. }\end{array}$ \\
\hline Beta-blockers & $\begin{array}{l}\text { Commonly prescribed for hypertension, heart disease, and migraine but } \\
\text { potentially dangerous in MG. May worsen MG. Use cautiously. }\end{array}$ \\
\hline Botulinum toxin & Presynaptic neuromuscular junction blocker. Avoid use. \\
\hline Chloroquine and hydroxychloroquine & $\begin{array}{l}\text { Used to treat/prevent malaria and for certain autoimmune diseases. May } \\
\text { precipitate de novo MG or worsen preexisting MG. Use only if necessary and } \\
\text { observe for worsening. }\end{array}$ \\
\hline
\end{tabular}

Corticosteroids

A standard treatment for MG but may cause transient worsening within the first 2 weeks. Monitor carefully for this possibility.

Desferrioxamine (deferoxamine)

Chelating agent used for hemochromatosis. May worsen MG.

D-Penicillamine

Used for Wilson disease and rarely for rheumatoid arthritis. Strongly associated with causing MG. Avoid use.

Fluoroquinolone antibiotics (e.g., ciprofloxacin, levofloxacin, moxifloxacin, and ofloxacin)

Commonly prescribed broad-spectrum antibiotics that are associated with worsening MG. The US FDA has designated a "black-box" warning for these agents in MG. Use cautiously, if at all.

Immune checkpoint inhibitors (e.g., ipilimumab, pembrolizumab,

Used for certain cancers. Can precipitate de novo MG or worsen preexisting atezolizumab, and nivolumab) MG. Use with caution as determined by oncologic status.

lodinated radiologic contrast agents

Older reports document increased MG weakness, but modern contrast agents appear safer. Use cautiously and observe for worsening.

Macrolide antibiotics (e.g., erythromycin, azithromycin, and clarithromycin)

Commonly prescribed antibiotics for gram-positive bacterial infections. May worsen MG. Use cautiously, if at all.

Magnesium

Potentially dangerous if given intravenously, i.e., for eclampsia during late pregnancy or for hypomagnesemia. Use only if absolutely necessary and observe for worsening.

Procainamide

Used for irregular heart rhythm. May worsen MG. Use with caution.

Quinine

Occasionally used for leg cramps. Use prohibited except in malaria in the United States.

Statins(e.g., atorvastatin, pravastatin, rosuvastatin, and simvastatin)

Used to reduce serum cholesterol. May rarely worsen or precipitate MG. Evaluate closely for worsening MG when statin treatment is commenced.

Telethromycin

Antibiotic for community-acquired pneumonia. Associated with hepatoxicity and risk of prolonged QTc interval. Causes severe, often fatal worsening in MG. Had been given a "black-box" warning by the US FDA contraindicating use in MG. Drug withdrawn from most markets internationally. Should not be used in MG.

Live-attenuated vaccines (measles, mumps, rubella, varicella zoster, intranasal influenza, oral polio, adenovirus type 4 and 7, Zostavax

Do not affect MG but are contraindicated in patients on immunosuppressive (herpes zoster), rotavirus, oral typhoid, smallpox, and yellow fever) treatments because of the risk for adverse reactions due to uninhibited growth of the attenuated live virus or bacteria.

Abbreviation: MG = myasthenia gravis.

${ }^{a}$ Many drugs are associated with worsening of MG. However, reported associations do not necessarily mean these medications should never be prescribed in MG. Reports are often rare or represent a coincidental association. Clinical judgment and the risk-to-benefit ratio of the drug should be considered when it is deemed important for a patient's treatment. Listed above are medications that have the strongest evidence for worsening MG.

The range outside of the "appropriate" category (7-9) indicates the breadth of opinions (dispersion) within the panel.

\section{Thymectomy}

The multicenter, randomized, rater-blinded trial of thymectomy in MG (MGTX) enrolled patients younger than 65 years with AChR-positive (AChR-Ab+) generalized nonthymomatous MG of $<5$ years duration. ${ }^{3}$ Sixty-six subjects underwent extended transsternal thymectomy and received prednisone using a standard dosing schedule, whereas 60 subjects received the standardized prednisone dosing schedule alone. An effect favoring thymectomy was seen in both of the coprimary outcome measures: reductions in the timeweighted average quantitative $\mathrm{MG}$ ( $\mathrm{QMG}$ ) score and the time-weighted average alternate-day prednisone dose. Secondary outcome measures, including azathioprine use, intravenous immunoglobulin (IVIg) use, and hospitalizations for MG exacerbations, also favored thymectomy plus prednisone. Benefits were seen within the first year and were sustained through year 3 . In a post hoc analysis, neither the 
prednisone dose nor QMG scores were significantly different between the 2 treatment groups in patients 50 years or older. ${ }^{3}$ An extension of the MGTX trial followed 68 (61\%) participants from the original trial for 2 additional years. At 60 months, lower time-weighted average QMG scores and a reduction in average time-weighted prednisone dose favored thymectomy plus prednisone. ${ }^{4}$ A recent AAN Practice Advisory recommended that clinicians should discuss thymectomy with patients with $\mathrm{AChR}-\mathrm{Ab}+$ generalized $\mathrm{MG}$ and should counsel patients considering minimally invasive thymectomy techniques that it is uncertain whether the benefit attained by extended transsternal thymectomy will also be attained by minimally invasive approaches (level B). ${ }^{5}$

\section{Recommendations}

1. a. In nonthymomatous, generalized MG patients with AChR-Ab, aged 18-50 years, thymectomy should be considered early in the disease to improve clinical outcomes and to minimize immunotherapy requirements and the need for hospitalizations for disease exacerbations (median 9, range 2-9). b. Thymectomy should be strongly considered in patients with $\mathrm{AChR}-\mathrm{Ab}+$ generalized MG if they fail to respond to an initial adequate trial of immunotherapy or have intolerable side effects from that therapy (median 9, range 5-9).

2. Thymectomy for MG is an elective procedure and should be performed when the patient is stable and deemed safe to undergo a procedure where postoperative pain and mechanical factors can limit respiratory function (median 9, range 8-9).

Recommendations 4 and 5 below are unchanged from the 2016 consensus guidance. ${ }^{1}$

3. Endoscopic and robotic approaches to thymectomy are increasingly performed and have a good track record for safety in experienced centers. Data from randomized, controlled comparison studies are not available. Based on comparisons across studies, less invasive thymectomy approaches appear to yield similar results to more aggressive approaches (median 9, range 4-9).

4. Thymectomy may be considered in patients with generalized MG without detectable AChR-Ab if they fail to respond adequately to immunosuppressive (IS) therapy or to avoid/ minimize intolerable adverse effects from IS therapy. Current evidence does not support an indication for thymectomy in patients with MuSK, low-density lipoprotein receptor-related protein 4, or agrin antibodies (median 9, range 6-9) (table e-3, doi:10.5061/dryad.6hdr7sqxx).

\section{Ocular MG}

A small RCT comparing prednisone with placebo in patients with 11 ocular MG who had previously failed to achieve minimal manifestation (MM) status after 4-6 weeks of pyridostigmine found that 5 of 6 participants $(83 \%)$ in the prednisone group achieved the primary end point of sustained MM status at a median of 14 weeks on prednisone (median dose $15 \mathrm{mg} / \mathrm{d}$ ), compared with none of 5 in the placebo group. ${ }^{6}$ Three of the 5 placebo participants switched to prednisone $(60 \mathrm{mg} / \mathrm{d})$ with rapid taper; 2 attained sustained MM status. A prospective cohort study of 13 consecutive ocular and 76 generalized MG patients evaluated the effect of IS agents on ophthalmoparesis. ${ }^{7}$ Fifty-nine percent of patients had complete resolution of ophthalmoparesis within $12 \pm 2$ months of initiation of IS agents. Patients with milder ophthalmoparesis had greater odds of symptom resolution in the first year of treatment. Median time to resolution was 7 months after IS agents were started.

Evidence for the efficacy of thymectomy in ocular MG is limited by the retrospective design of most published studies. In a case-control study of 47 patients with nonthymomatous ocular MG who underwent thymectomy matched to $67 \mathrm{pa}-$ tients who refused surgery, there was no difference in the proportion of patients achieving stable remission at a median follow-up of 100-116 months. ${ }^{8}$ A retrospective analysis of 236 patients with thymomatous and nonthymomatous MG reported no improvement after thymectomy in 25 patients, of whom 17 (68\%) were ocular or predominantly ocular, over 12 months of follow-up. ${ }^{9}$ In another retrospective case series of 52 patients with MG, only 2 of 11 patients with ocular MG (18\%) achieved remission after thymectomy, in contrast to $28 \%-50 \%$ of patients with generalized MG. ${ }^{10}$

A retrospective case series of 110 patients with ocular MG who underwent extended transsternal thymectomy reported that at a median follow-up of 33.5 months, $26 \%$ achieved complete remission (defined as asymptomatic without medications for 12 months). ${ }^{11}$ Five patients had a thymoma. ${ }^{11}$ A retrospective case series of 49 nonthymomatous ocular MG and 12 ocular MG with thymoma undergoing thymectomy followed for a mean duration of 9 years reported a cure defined as asymptomatic without the need for medications in $51 \% .{ }^{12}$ In yet another retrospective case series of transcervical thymectomy in MG, 57\% of 12 patients with ocular MG achieved MGFA postintervention status (PIS) of complete stable remission $(\mathrm{CSR})^{13}$ at 5 years. ${ }^{14}$ A subsequent case series of 151 patients with MG who underwent transcervical thymectomy followed for 5 years showed a higher odds ratio for remission in ocular MG compared with generalized MG without controlling for other variables (analysis performed by P.N.). ${ }^{15}$ In 12 patients with ocular MG undergoing thymectomy because of an abnormal chest $\mathrm{CT}$ scan, all but one required additional immunosuppression after thymectomy; 6 achieved remission at a mean follow-up of 81 months. ${ }^{16}$ In a retrospective analysis of 50 patients with juvenile MG undergoing thymectomy, of whom $46 \%$ were ocular, $50 \%$ showed improved PIS at a mean of 3.5 years of follow-up. ${ }^{17}$ There was no difference between ocular and generalized MG. In a metaanalysis of 26 studies of thymectomy in nonthymomatous MG, the pooled CSR rate was $0.51{ }^{18}$ There was high heterogeneity in the meta-analysis model, indicating substantial differences among the included studies. 


\section{Recommendations}

1. Ophthalmoparesis or ptosis in ocular MG that is not responding to anticholinesterase agents should be treated with immunosuppressant agents if symptoms are functionally limiting or troublesome to the patient (median 9, range 7-9).

2. Corticosteroids should be used as the initial IS agent in ocular MG. Steroid-sparing IS agents may be needed when corticosteroids alone are ineffective, contraindicated, or not tolerated (median 9, range 6-9).

3. Data from a single small RCT suggest that low-dose corticosteroids may be effective for ocular MG and may avoid side effects associated with high-dose corticosteroids (median 9, range 4-9).

4. AChR-Ab+ patients with ocular MG who do not respond adequately to acetylcholinesterases and who either prefer not to take IS therapy or have contraindications to or are refractory to IS agents may be offered thymectomy (median 8, range 5-9) (table e-10, doi:10.5061/dryad.6hdr7sqxx).

\section{Rituximab}

Most studies of RTX are retrospective, and some combine patients with AChR-Ab, MuSK-Ab, and seronegative MG. A multicenter blinded prospective review of MuSK-Ab + MG patients demonstrated that 14 of 24 (58\%) patients treated with RTX achieved MM status and required only low-dose IS therapy, compared with 5 of 31 (16\%) of the non-RTX group. ${ }^{19}$

In a prospective open-label study of 22 refractory $A C h R-A b+$, $\mathrm{MuSK}-\mathrm{Ab}+$, and seronegative MG, MG manual muscle testing (MMT) scores revealed significant improvement from baseline at a mean follow-up of $29 \pm 19$ months in the AChR-Ab+ and MuSK-Ab+ groups. ${ }^{20}$ Another prospective open-label study of 14 patients with refractory AChR-Ab+, MuSK-Ab+, and seronegative MG reported improvement in MMT scores at a mean followup of 22 months. ${ }^{21}$ The time to peak response after a single cycle of RTX was $4.5 \pm 1$ months. A retrospective multicenter study of MuSK-Ab + MG reported that RTX given in the dose of $375 \mathrm{mg} /$ $\mathrm{m}^{2}$ weekly for 4 weeks and then monthly for the next 2 months was associated with lower relapse rates (18\%) compared with a regimen of two $1 \mathrm{~g}$ infusions separated by 2 weeks $(80 \%) .{ }^{22} \mathrm{~A}$ retrospective Austrian nationwide study of 56 patients with $\mathrm{AChR}-\mathrm{Ab}+$ and MuSK-Ab $+\mathrm{MG}$ reported that $26 \%$ of patients were in remission 3 months after treatment with varying dosing protocols of RTX. At a median of 20 months, $43 \%$ were in remission and $25 \%$ achieved $\mathrm{MM}$ status. ${ }^{23} \mathrm{~A}$ single-center retrospective study of $21 \mathrm{AChR}-\mathrm{Ab}+, 3 \mathrm{MuSK}-\mathrm{Ab}+$, and 4 patients with double-seronegative MG found that muscle strength improved significantly from baseline at 6 months and then stabilized up to 36 months, and PIS was improved in $43 \%$ at 6 months. ${ }^{24} \mathrm{~A}$ retrospective combined analysis of previously published case reports of 169 patients between January 2000 and August 2015 reported that $72 \%$ of MuSK-Ab + MG and 30\% of AChR-Ab+ MG patients treated with RTX achieved MM status or better. ${ }^{25}$ The number of cycles of RTX varied but did not have an effect on the response. A recent systematic review of previous studies of 165 patients with AChR-Ab+ MG treated with RTX concluded that despite heterogeneous outcome measures, significant clinical improvement was seen in 113 patients (68\%), with 36\% achieving remission. ${ }^{26}$ A phase II RCT of RTX (Beat-MG) enrolled 52 patients with generalized nonthymomatous $\mathrm{AChR}-\mathrm{Ab}+$ MG on a stable regimen of prednisone for 4 weeks or prednisone plus another IS agent for 6 months. ${ }^{27}$ Two cycles of RTX 6 months apart were compared to placebo with the primary outcome being a steroid-sparing effect $(\geq 75 \%$ reduction in mean daily prednisone requirements in the 4 weeks before week 52 compared with the 4-week period before randomization). The study was designed to assess futility (nonsuperiority). Preliminary results reported that the area under the curve for prednisone was not significantly different between RTX and placebo groups, with $60 \%$ on RTX and $56 \%$ on placebo achieving the primary outcome. There were no significant differences in mean QMG or MG-composite (MGC) changes between the groups. The study suggests that in mildly to moderately symptomatic generalized $\mathrm{AChR}-\mathrm{Ab}+\mathrm{MG}$, RTX is unlikely to have a clinically meaningful steroid-sparing effect over 12 months.

Three cases of progressive multifocal leukoencephalopathy have been reported in MG. One was RTX related, although the patient had previously received other IS agents, ${ }^{28}$ another patient was on azathioprine and prednisone, ${ }^{29}$ and the third patient was on prednisolone, IVIg, and azathioprine. ${ }^{30}$

\section{Recommendations}

Recommendation 1 is unchanged from the 2016 consensus guidance. ${ }^{1}$

1. Rituximab should be considered as an early therapeutic option in patients with MuSK-Ab+ MG who have an unsatisfactory response to initial immunotherapy (median 9, range 4-9).

2. The efficacy of RTX in refractory AChR-Ab+ MG is uncertain. It is an option if patients fail or do not tolerate other IS agents (median 8, range 4-9) (tables e-2 and e-7, doi:10.5061/dryad.6hdr7sqxx).

\section{Methotrexate}

Studies on the use of MTX in MG are limited, and the available data do not provide convincing evidence of efficacy. In a retrospective case series of 16 patients with MG treated with MTX, (abstract only) 8 patients reduced pyridostigmine doses and 6 showed "clinical improvement." ${ }^{31}$ A prospective open-label case series published only as an abstract reported that 14 of 16 patients with MG treated with MTX had an improved PIS on a mean follow-up of 20.6 months. ${ }^{32}$ In a single-blinded trial, 24 patients with generalized MG on prednisone were randomized to MTX (11) or azathioprine (13). ${ }^{33}$ At 24 months, the average prednisone dose required to achieve and maintain $\mathrm{MM}$ status was lower in both MTX- and azathioprine-treated patients but was not different between the groups. At months 10 and 12, the prednisone dose was lower in the MTX group, but the confidence interval includes clinically meaningful and nonmeaningful effects. Similar proportions of both groups achieved MM status, and there were no differences in QMG or MG-activity of daily 
living (MG-ADL) scores between the groups. ${ }^{33}$ An RCT enrolled 50 patients with AChR-Ab+ MG taking prednisone at a dose of $\geq 10 \mathrm{mg} / \mathrm{d}$. ${ }^{34}$ Patients were randomized 1:1 to MTX 20 $\mathrm{mg} / \mathrm{wk}$ or placebo. There was no difference in the primary outcome measure, the area under the prednisone dose-time curve between months 4 and 12, and the mean 12-month change in QMG, MMT, MG-Quality of life, MG-ADL, and MGC was no different between treatment groups.

\section{Recommendation}

1. Although evidence from RCTs is lacking, oral MTX may be considered as a steroid-sparing agent in patients with generalized MG who have not tolerated or responded to steroid-sparing agents that are better supported by RCT data (median 9, range 5-9) (table e-2, doi:10.5061/ dryad.6hdr7sqxx).

\section{Eculizumab}

Eculizumab is a humanized monoclonal antibody against the terminal C5 complement molecule. ${ }^{35}$ Eculizumab prevents the formation of the membrane attack complex and reduces damage caused by complement-fixing AChR antibodies. ${ }^{36}$ In a phase II crossover RCT of 14 patients with refractory generalized AChR$\mathrm{Ab}+\mathrm{MG}$, at the end of the first treatment period, 6/7 (86\%) of eculizumab-treated patients achieved the primary end point of a 2-point reduction in the QMG score, compared to $57 \%$ with placebo. ${ }^{37}$ A repeated measures mixed model of data from all visits revealed significant differences in the QMG score favoring eculizumab. Eculizumab was well tolerated. In a phase III international multicenter RCT of 125 patients with refractory generalized nonthymomatous AChR-Ab+ MG (REGAIN), the primary outcome measure of change in the MG-ADL score from baseline to week 26 , measured by worst-rank analysis of covariance, was not significantly different $(p=0.0698)$ between eculizumab and placebo arms. ${ }^{38}$ However, QMG score change on worst-rank analysis of covariance, all prespecified secondary endpoints (changes in QMG, MGC, and MG-QOL15 scores and responder analyses of QMG and MG-ADL scores), and multiple sensitivity analyses showed a significant benefit for eculizumab. Participants who completed the 26-week REGAIN study were followed in an open-label extension (OLE) within 2 weeks of completing REGAIN. ${ }^{39}$ A preplanned interim analysis of the OLE at 22.7 months of median follow-up found a reduction in MG exacerbations by $75 \%$ compared with the year before REGAIN. In addition, 56\% (65/116) of patients achieved MM status or pharmacologic remission. The magnitude of response on all clinical measures for the placebo patients in REGAIN who crossed over to receive eculizumab in the OLE was similar to the eculizumab-treated patients in REGAIN. A clinically meaningful response in MG-ADL and QMG scores was seen in 55\% and $39.7 \%$ of patients, respectively. Eculizumab was well tolerated. One case of meningococcal meningitis occurred, despite vaccination in the OLE and the patient was successfully treated.

Vaccination against Neisseria meningitidis (both meningococcal conjugate Men ACWY and serogroup B or MenB) is required at least 2 weeks before starting treatment with eculizumab. The conjugate ACWY vaccines available in the United States include Menveo (1 dose, GlaxoSmithKline Biologicals, Inc.) and Menactra (1 dose, single booster 4 years after initial dose if needed, Sanofi Pasteur, Inc.). The 2 brands of MenB vaccine are Bexsero (2 dose series, GlaxoSmithKline Biologicals, Inc.) and Trumenba ( 3 dose series, Pfizer, Inc.). The brands are not interchangeable, and a course should be completed with the same brand of the vaccine for all doses. The vaccine does not confer absolute protection against meningococcal meningitis. Antibiotic coverage, for at least 4 weeks after immunization, is recommended if eculizumab is started before the 2 -week period after vaccination. The recommendations for antibiotic coverage vary. Penicillin VK $250-500 \mathrm{mg}$ every 12 hours is usually the first-line chemoprophylaxis. ${ }^{40,41}$ Erythromycin $500 \mathrm{mg}$ twice daily, azithromycin $500 \mathrm{mg}$ daily, or ciprofloxacin $500 \mathrm{mg}$ daily are alternatives for penicillin-allergic patients. ${ }^{40-42}$ However, both fluoroquinolones and macrolides can worsen MG. Chemoprophylaxis of meningococcal infections in penicillinallergic patients can therefore be challenging, and infectious disease consultation may be required.

\section{Recommendations}

1. Eculizumab should be considered in the treatment of severe, refractory, AChR-Ab+ generalized MG (median 9, range 2-9).

2. The role of eculizumab in the treatment of MG is likely to evolve over time. Until further data become available to allow comparisons of cost and efficacy with other treatments, eculizumab should be considered after trials of other immunotherapies have been unsuccessful in meeting treatment goals (median 9, range 5-9).

3. Recommendations of the Advisory Committee on Immunization Practices or other local guidelines regarding immunization against meningococcal meningitis should be followed before treatment with eculizumab (median 9, range 8-9).

4. Future research should include assessment of the duration of eculizumab therapy necessary to achieve and maintain treatment goals, its efficacy in other MG populations (MG with thymoma and seronegative $\mathrm{MG}$ ), and in other stages of disease (MG crises, exacerbations, and early therapy in nonrefractory AChR-Ab+ MG) (median 8, range 4-9) (table e-2, doi:10.5061/dryad.6hdr7sqxx).

\section{Immune Checkpoint Inhibitors}

Immune checkpoints (ICPs) are most often inhibitory molecules expressed on the surface of $\mathrm{T}$ cells, which modulate the immune response and prevent host tissue damage due to uncontrolled responses to foreign or self-antigens. The immune inhibitory cytotoxic T-lymphocyte-associated protein 4 (CTLA-4), programmed cell death protein 1 (PD-1), and programmed cell death ligand 1 (PD-L1) are the best-characterized ICPs and are targeted in cancer immunotherapy. CTLA-4 reduces T-cell activation, competing with $\mathrm{CD} 28$ in binding $\mathrm{B} 7$ molecules (CD80 and CD86) on antigen-presenting cells. PD-1 binds its ligands (PD-L1 and PD-L2) and reduces activated T-cell proliferation through the inhibition of specific phosphorylation pathways. ${ }^{43,44}$ 
Monoclonal antibodies against CTLA-4, PD-1, and PD-L1 act by blocking these inhibitory ICP molecules to stimulate antitumor immunity (immune checkpoint inhibitors [ICIs]). These include the CTLA-4 inhibitor ipilimumab, PD-1 inhibitors pembrolizumab, nivolumab, and cemiplimab, and the PDL-1 inhibitors atezolizumab, durvalumab, and avelumab. Because of the upregulation of the immune response, multisystem immunerelated adverse events (irAEs) such as skin rash, thyroid dysfunction, pneumonitis, colitis, hepatitis, nephritis, hypophysitis, and neurologic disorders including $M G$ have been reported in patients receiving checkpoint inhibitors.

The literature on irAEs of these drugs is rapidly evolving. De novo MG has been reported in patients treated with antiCTLA-4 agents (ipilimumab), ${ }^{45} \mathrm{PD}-1$ inhibitors (nivolumab or pembrolizumab), ${ }^{45-47}$ and with combined (anti-CTLA-4 plus anti-PD-1 or PD-L1) therapy. ${ }^{45}$ The estimated frequency of MG among patients treated with PD-1 inhibitors ranges from $0.12 \%$ to $0.2 \%{ }^{48-52}$ Exacerbation of preexisting MG and subclinical AChR-Ab+ MG has been reported in patients treated with PD-1 inhibitors. ${ }^{45,53,54}$

MG onset or exacerbation varies in severity and generally occurs in the early phase of treatment. MG can overlap with other immunemediated peripheral and central neurologic syndromes. ${ }^{48,55}$ In a review of the literature combined with a single-center experience, of 63 patients with MG due to ICIs, 52 had new-onset MG and 11 had a flare of preexisting MG. Most received PD-1 therapy. Concurrent myositis was diagnosed in 24 patients (37\%) and myocarditis in 5 (8\%); 2 had the triad of MG/myositis/myocarditis. Median time from ICI initiation to developing MG was 4 weeks (6 days-16 weeks). Respiratory failure requiring mechanical ventilation occurred in 29 patients (45\%). Patients with MG/myositis/ myocarditis developed respiratory failure more frequently than those with MG alone ( $54 \%$ vs $42 \%$ ). AChR-Ab titers were elevated in 37/56 (66\%) of tested patients. Three patients had AChR-Ab when tested before ICI initiation and antibody titers increased at least 2-fold after ICI initiation. Intravenous corticosteroids were used in 59 of 63 patients. Thirty-eight patients received steroids as first-line therapy and 24 (63\%) improved. Four patients with ocular MG developed respiratory insufficiency after corticosteroid treatment. MG symptoms completely resolved in 12 patients (19\%), improved in 34 (55\%), and worsened in $16(26 \%) .{ }^{51}$ In a review of 1834 patients receiving ICIs, 4 had MG, of whom 1 was AChR$\mathrm{Ab}+$. Three were associated with myositis. Three patients with MG received combined CTLA-4 and PD-1 ICIs and one received a CTLA-4 ICI. Concurrent occurrence of MG with myocarditis and thyroiditis was also noted. ${ }^{50}$ The diagnosis of ICI-related MG can be challenging. Many patients with cancer have fatigue or generalized weakness. The recognition of the underlying neuromuscular disease may be delayed by the focus on the oncologic illness. Concurrent myositis may make MG difficult to diagnose especially when associated with ocular and bulbar weakness. Seronegative MG appears to be more frequent in these patients, making the diagnosis even more challenging. ${ }^{50}$ The severity of the illness may be the result of multiple concurrent conditions including MG, myositis, and myocarditis. CNS involvement may occur in conjunction with MG or MG-myositis overlap. ${ }^{50}$ Corticosteroid therapy appears to result in favorable outcomes. ${ }^{50}$

\section{Recommendations}

1. The risk of MG and other immune-mediated neurologic illnesses should be discussed with patients who are candidates for ICIs (median 9, range 5-9).

2. At this time, there is no evidence to either support or refute the utility of AChR antibody testing in patients without MG before starting ICIs (median 8, range 7-9).

3. MG associated with ICIs is generally severe, with a high rate of respiratory crises (median 8, range 5-9).

4. Preexisting MG does not constitute an absolute contraindication to the use of ICIs, at least in patients with well-controlled disease (MM status or better). However, in these patients:

- It may be prudent to avoid combined therapy (anti-CTLA-4 plus anti-PD-1/PD-L1 monoclonal antibodies), given the higher potential for severe irAEs.

- Close clinical monitoring, particularly of respiratory and bulbar function, is mandatory.

- Although the therapeutic response to ICIs seems to be less satisfactory in patients receiving immunosuppressants, MG treatment should be maintained and may even be restarted in patients whose $\mathrm{MG}$ is in remission before treatment with ICIs (median 8, range 5-9).

5. Early aggressive treatment with high-dose steroids in combination with plasma exchange or IVIg may be required in patients who develop overt MG while on ICIs. The decision to withdraw ICIs is determined by the oncologic status (median 8, range 7-9) (table e-9, doi:10.5061/dryad. 6hdr7sqxx).

\section{Discussion}

This is an updated formal international consensus guidance of MG experts, based on new evidence that has become available since the initial guidance was published in 2016. ${ }^{1}$ As before, these statements are intended as a guide for clinicians worldwide and are not absolute recommendations for management. They are also not intended for establishing payment policies or drug tiering by payers. This continues to be a living document, which will require periodic review and updates to reflect new information relevant to the management of MG.

\section{Acknowledgment}

The authors acknowledge the support of the Myasthenia Gravis Foundation of America.

\section{Study Funding}

No targeted funding reported.

\section{Disclosure}

P. Narayanaswami: Research support: Momenta Pharmaceuticals, PCORI, Advisory board: Argenx, Alexion, Member, 
Medical and Scientific Advisory Board, and Myasthenia Gravis Foundation of America (MGFA). D.B. Sanders: Research support from PCORI, Consultant for Accordant Health Services, Alexion, Cabaletta, Janssen RnD, Kashiv Biosciences, and Momenta Pharmaceuticals. G.I. Wolfe: Advisory board for Grifols, Alexion, Takeda, BPL, UCB, ArgenX, Ra. Research support from ArgenX, Ra, Immunovant, and MGFA. M. Benatar: Advisory Boards: Immunovant, Viela Bio; Site-PI on industry trials: UCB; federal funding: Site-PI for MGNet (U54115054). G. Cea: No relevant disclosures. A. Evoli: Scientific award jury member for Grifols and a safety data monitor for UCB. N. E.Gilhus: Consultant for Ra Pharma, Argenx, and UCB. Speakers' honoraria from Octapharma, Alexion, and Merck Serono. I. Illa: Consultant and Scientific award jury member for Grifols; N. L. KuntzL: Medical advisory boards for Argenx, Audentes, AveXis, Biogen, Cytokinetics, Roche, and Sarepta; J. M. Massey: Site PI, Revance Therapeutics. Melms A: Advisory board, UCB; H. Murai: Consultant for Alexion, Argenx, and Ra, speaker honoraria from the Japan Blood Products Organization, research support from the Ministry of Health, Labour and Welfare, Japan. J. Palace: partly funded by highly specialized services to run a national congenital myasthenia service and a neuromyelitis service, support for scientific meetings and honorariums for advisory work from Merck Serono, Biogen Idec, Novartis, Teva, Chugai Pharma, and Bayer Schering, Alexion, Roche, Genzyme, MedImmune, EuroImmun, MedDay, Abide ARGENX, UCB and Viela Bio and grants from Merck Serono, Novartis, Biogen Idec, Teva, Abide, MedImmune, Bayer Schering, Genzyme, Chugai, and Alexion. She has received grants from the MS society, Guthrie Jackson Foundation, NIHR, Oxford Health Services Research Committee, EDEN, MRC, GMSI, John Fell, and Myaware for research studies. D. P. Richman: Research funding from the NINDS (1R21NS104516), Myasthenia Gravis Foundation of America, and Cabaletta Bio Inc. Member of the Advisory Board of Cabaletta Bio Inc. J. Verschuuren: receives financial support from Target to B consortium, Prinses Beatrix Spierfonds, and has been involved in trials or consultancies for Argenx, Alexion, or Ra pharma. Member of the European Reference Network for Rare Neuromuscular Diseases [ERN EURO-NMD]. Go to Neurology.org/ $\mathrm{N}$ for full disclosures.

\section{Publication History}

Received by Neurology May 12, 2020. Accepted in final form October 8, 2020.

Appendix Authors

\begin{tabular}{lll}
\hline Name & Location & Contribution \\
\hline Pushpa & Beth Israel Deaconess & Study concept and \\
Narayanaswami, & Medical Center/Harvard & design, acquisition of \\
MBBS, DM & Medical School, Boston, & data, analysis of \\
& MA & data, drafting/ \\
& revising the \\
& manuscript, and \\
& study supervision. \\
\hline
\end{tabular}

\section{Appendix (continued)}

\begin{tabular}{|c|c|c|}
\hline Name & Location & Contribution \\
\hline $\begin{array}{l}\text { Donald B. } \\
\text { Sanders, MD }\end{array}$ & $\begin{array}{l}\text { Duke University Medical } \\
\text { Center, Durham, NC }\end{array}$ & $\begin{array}{l}\text { Study concept and } \\
\text { design, acquisition of } \\
\text { data, drafting/revising } \\
\text { the manuscript, and } \\
\text { study supervision. }\end{array}$ \\
\hline Gil Wolfe, MD & $\begin{array}{l}\text { Univ. at Buffalo Jacobs } \\
\text { School of Medicine and } \\
\text { Biomedical Sciences, } \\
\text { State University of New } \\
\text { York, Buffalo, NY }\end{array}$ & $\begin{array}{l}\text { Study concept and } \\
\text { design, acquisition of } \\
\text { data, drafting/revising } \\
\text { the manuscript, and } \\
\text { study supervision. }\end{array}$ \\
\hline $\begin{array}{l}\text { Michael Benatar, } \\
\text { MD, PhD }\end{array}$ & $\begin{array}{l}\text { University of Miami, } \\
\text { Miller School of } \\
\text { Medicine, Miami, FL }\end{array}$ & $\begin{array}{l}\text { Acquisition of data and } \\
\text { drafting/revising the } \\
\text { manuscript for } \\
\text { intellectual content }\end{array}$ \\
\hline Gabriel Cea, MD & $\begin{array}{l}\text { Facultad de Medicina, } \\
\text { Universidad de Chile, } \\
\text { Santiago, Chile }\end{array}$ & $\begin{array}{l}\text { Acquisition of data and } \\
\text { drafting/revising the } \\
\text { manuscript for } \\
\text { intellectual content }\end{array}$ \\
\hline Amelia Evoli, MD & $\begin{array}{l}\text { Fondazione Policlinico } \\
\text { Universitario "A. Gemelli" } \\
\text { IRCCS, Università } \\
\text { Cattolica del Sacro } \\
\text { Cuore, Roma, Italy }\end{array}$ & $\begin{array}{l}\text { Acquisition of data and } \\
\text { drafting/revising the } \\
\text { manuscript for } \\
\text { intellectual content }\end{array}$ \\
\hline
\end{tabular}

\begin{tabular}{lll}
\hline $\begin{array}{l}\text { Nils Erik Gilhus, } \\
\text { MD }\end{array}$ & $\begin{array}{l}\text { University of Bergen, } \\
\text { Norway }\end{array}$ & $\begin{array}{l}\text { Acquisition of data and } \\
\text { drafting/revising the } \\
\text { manuscript for } \\
\text { intellectual content }\end{array}$ \\
\hline
\end{tabular}

\begin{tabular}{lll}
\hline Isabel IIIa, MD & Hospital Santa Creu i & $\begin{array}{l}\text { Acquisition of data and } \\
\text { Sant Pau. Universitat } \\
\text { Autonoma de Barcelona, } \\
\text { manuscript for }\end{array}$ \\
& $\begin{array}{l}\text { Barcelona, ERN EURO- } \\
\text { NMD and CIBERER U762, } \\
\text { Spain }\end{array}$ & \\
& intellectual content \\
& & \\
\hline
\end{tabular}

\begin{tabular}{lll}
\hline $\begin{array}{l}\text { Nancy L. Kuntz, } \\
\text { MD }\end{array}$ & $\begin{array}{l}\text { Northwestern Feinberg } \\
\text { School of Medicine, } \\
\text { Chicago, IL }\end{array}$ & $\begin{array}{l}\text { Acquisition of data and } \\
\text { drafting/revising the } \\
\text { manuscript for } \\
\text { intellectual content }\end{array}$ \\
\hline
\end{tabular}

Janice M. Massey, Duke University Medical Acquisition of data and
MD $\quad$ Center, Durham, NC drafting/revising the manuscript for intellectual content

\begin{tabular}{lll}
\hline $\begin{array}{l}\text { Arthur Melms, } \\
\text { MD }\end{array}$ & $\begin{array}{l}\text { University of Tübingen } \\
\text { Medical Centre, } \\
\text { Tübingen, Germany }\end{array}$ & $\begin{array}{l}\text { Acquisition of data and } \\
\text { drafting/revising the } \\
\text { manuscript for } \\
\text { intellectual content }\end{array}$ \\
\hline
\end{tabular}

Hiroyuki Murai, International University Acquisition of data and
MD of Health and Welfare, drafting/revising the Narita, Japan manuscript for intellectual content

\begin{tabular}{lll}
\hline Michael Nicolle, & Western University, \\
MD & London, ON, Canada & $\begin{array}{l}\text { Acquisition of data and } \\
\text { drafting/revising the } \\
\text { manuscript for } \\
\text { intellectual content }\end{array}$ \\
\hline
\end{tabular}

\begin{tabular}{lll}
\hline $\begin{array}{l}\text { Jacqueline } \\
\text { Palace, BM, DM }\end{array}$ & $\begin{array}{l}\text { John Radcliffe Hospital, } \\
\text { Oxford University } \\
\text { Hospitals Trust, Oxford, } \\
\text { UK }\end{array}$ & $\begin{array}{l}\text { Acquisition of data and } \\
\text { drafting/revising the } \\
\text { manuscript for } \\
\text { intellectual content }\end{array}$ \\
\hline $\begin{array}{l}\text { David P. } \\
\text { Richman, MD }\end{array}$ & $\begin{array}{l}\text { University of California, } \\
\text { Davis, Davis, CA }\end{array}$ & $\begin{array}{l}\text { Acquisition of data and } \\
\text { drafting/revising the } \\
\text { manuscript for } \\
\text { intellectual content }\end{array}$ \\
\hline
\end{tabular}

Continued 
Appendix (continued)

\begin{tabular}{lll}
\hline Name & Location & Contribution \\
\hline $\begin{array}{ll}\text { Jan Verschuuren, } \\
\text { MD }\end{array}$ & $\begin{array}{l}\text { Leiden University } \\
\text { Medical Center, Leiden, } \\
\text { the Netherlands }\end{array}$ & $\begin{array}{l}\text { Acquisition of data and } \\
\text { drafting/revising the } \\
\text { manuscript for } \\
\text { intellectual content }\end{array}$ \\
\hline
\end{tabular}

\section{References}

1. Sanders DB, Wolfe GI, Benatar M, et al. International consensus guidance for management of myasthenia gravis: executive summary. Neurology 2016;87:419-425.

2. Fitch K, Bernstein SJ, Aguilar MD, et al. The RAND/UCLA Appropriateness Method User's Manual. [online]. Available at: rand.org/pubs/monograph_reports/MR1269. html. Accessed July 10, 2020.

3. Wolfe GI, Kaminski HJ, Aban IB, et al. Randomized trial of thymectomy in myasthenia gravis. N Engl J Med 2016;375:511-522.

4. Wolfe GI, Kaminski HJ, Aban IB, et al. Long-term effect of thymectomy plus prednisone versus prednisone alone in patients with non-thymomatous myasthenia gravis: 2-year extension of the MGTX randomised trial. Lancet Neurol 2019;18:259-268.

5. Gronseth GS, Barohn R, Narayanaswami P. Practice advisory: thymectomy for myasthenia gravis (practice parameter update): report of the guideline development, dissemination, and implementation subcommittee of the American Academy of Neurology. Neurology 2020;94:705-709.

6. Benatar M, McDermott MP, Sanders DB, et al. Efficacy of prednisone for the treatment of ocular myasthenia (EPITOME): a randomized, controlled trial. Muscle Nerve 2016;53:363-369.

7. Europa TA, Nel M, Heckmann JM. Myasthenic ophthalmoparesis: time to resolution after initiating immune therapies. Muscle Nerve 2018;58:542-549.

8. Mineo TC, Ambrogi V. Outcomes after thymectomy in class I myasthenia gravis. J Thorac Cardiovasc Surg 2013;145:1319-1324.

9. Evoli A, Batocchi AP, Provenzano C, Ricci E, Tonali P. Thymectomy in the treatment of myasthenia gravis: report of 247 patients. J Neurol 1988;235:272-276.

10. Hatton PD, Diehl JT, Daly BDT, et al. Transsternal radical thymectomy for myasthenia gravis: a 15-year review. Ann Thorac Surg 1989;47:838-840.

11. Liu Z, Feng H, Yeung S-CJ, et al. Extended transsternal thymectomy for the treatment of ocular myasthenia gravis. Ann Thorac Surg 2011;92:1993-1999.

12. Roberts PF, Venuta F, Rendina E, et al. Thymectomy in the treatment of ocular myasthenia gravis. J Thorac Cardiovasc Surg 2001;122:562-568.

13. Jaretzki A III, Barohn RJ, Ernstoff RM, et al. Myasthenia gravis: recommendations for clinical research standards. Task Force of the medical scientific advisory board of the Myasthenia Gravis Foundation of America. Neurology 2000;55:16-23.

14. Shrager JB, Deeb ME, Mick R, et al. Transcervical thymectomy for myasthenia gravis achieves results comparable to thymectomy by sternotomy. Ann Thorac Surg 2002; 74:320-326; discussion 326-327.

15. Shrager JB, Nathan D, Brinster CJ, et al. Outcomes after 151 extended transcervical thymectomies for myasthenia gravis. Ann Thorac Surg 2006;82:1863-1869.

16. Sommer N, Sigg B, Melms A, et al. Ocular myasthenia gravis: response to long-term immunosuppressive treatment. J Neurol Neurosurg Psychiatry 1997;62:156-162.

17. Kim AG, Upah SA, Brandsema JF, Yum SW, Blinman TA. Thoracoscopic thymectomy for juvenile myasthenia gravis. Pediatr Surg Int 2019;35:603-610.

18. Zhu K, Li J, Huang X, et al. Thymectomy is a beneficial therapy for patients with nonthymomatous ocular myasthenia gravis: a systematic review and meta-analysis. Neurol Sci 2017;38:1753-1760.

19. Hehir MK, Hobson-Webb LD, Benatar M, et al. Rituximab as treatment for antiMuSK myasthenia gravis: multicenter blinded prospective review. Neurology 2017; 89:1069-1077.

20. Beecher G, Anderson D, Siddiqi ZA. Rituximab in refractory myasthenia gravis: extended prospective study results. Muscle \& Nerve 2018;58:452-455.

21. Anderson D, Phan C, Johnston WS, Siddiqi ZA. Rituximab in refractory myasthenia gravis: a prospective, open-label study with long-term follow-up. Ann Clin Translational Neurol 2016;3:552-555.

22. Cortés-Vicente E, Rojas-Garcia R, Díaz-Manera J, et al. The impact of rituximab infusion protocol on the long-term outcome in anti-MuSK myasthenia gravis. Ann Clin Translational Neurol 2018;5:710-716.

23. Topakian R, Zimprich F, Iglseder S, et al. High efficacy of rituximab for myasthenia gravis: a comprehensive nationwide study in Austria. J Neurol 2019;266:699-706.

24. Afanasiev V, Demeret S, Bolgert F, Eymard B, Laforet P, Benveniste O. Resistant myasthenia gravis and rituximab: a monocentric retrospective study of 28 patients. Neuromuscul Disord 2017;27:251-258.

25. Tandan R, Hehir MK, Waheed W, Howard DB. Rituximab treatment of myasthenia gravis: a systematic review. Muscle Nerve 2017;56:185-196.
26. Di Stefano V, Lupica A, Rispoli MG, Di Muzio A, Brighina F, Rodolico C. Rituximab in AChR subtype of myasthenia gravis: systematic review. J Neurol Neurosurg Psychiatry 2020;91:392-395.

27. Nowak RJ, Coffey C, Goldstein J. AAN 2018 Emerging science abstracts: B-cell targeted treatment in myasthenia gravis (BeatMG) - a phase 2 trial of rituximab in myasthenia gravis: topline results. Neurology 2018;90:e2182-e2194.

28. Kanth KM, Solorzano GE, Goldman MD. PML in a patient with myasthenia gravis treated with multiple immunosuppressing agents. Neurol Clin Pract 2016;6:e17-e19.

29. Dawson DM. Progressive multifocal leukoencephalopathy in myasthenia gravis. Ann Neurol 1982;11:218-219.

30. Gedizlioglu M, Coban P, Ce P, Sivasli IE. An unusual complication of immunosuppression in myasthenia gravis: progressive multifocal leukoencephalopathy. Neuromuscul Disord 2009;19:155-157.

31. Hartman J, Rivner MH. Methotrexate in myasthenia gravis. Clin Neurophysiol 2009; 120:e123-e124

32. Abdou A. Methotrexate for treatment of myasthenia gravis. Neurology 2007;68:A300.

33. Heckmann JM, Rawoot A, Bateman K, Renison R, Badri M. A single-blinded trial of methotrexate versus azathioprine as steroid-sparing agents in generalized myasthenia gravis. BMC Neurol 2011;11:97.

34. Pasnoor $\mathrm{M}, \mathrm{He} \mathrm{J}$, Herbelin $\mathrm{L}$, et al. A randomized controlled trial of methotrexate for patients with generalized myasthenia gravis. Neurology 2016;87:57-64.

35. Dhillon S. Eculizumab: a review in generalized myasthenia gravis. Drugs $2018 ; 78$ 367-376.

36. Rother RP, Rollins SA, Mojcik CF, Brodsky RA, Bell L. Discovery and development of the complement inhibitor eculizumab for the treatment of paroxysmal nocturnal hemoglobinuria. Nat Biotechnol 2007;25:1256-1264.

37. Howard JF Jr, Barohn RJ, Cutter GR, et al. A randomized, double-blind, placebocontrolled phase II study of eculizumab in patients with refractory generalized myasthenia gravis. Muscle Nerve 2013;48:76-84.

38. Howard JF Jr, Utsugisawa K, Benatar M, et al. Safety and efficacy of eculizumab in anti-acetylcholine receptor antibody-positive refractory generalised myasthenia gravis (REGAIN): a phase 3, randomised, double-blind, placebo-controlled, multicentre study. Lancet Neurol 2017;16:976-986.

39. Muppidi S, Utsugisawa K, Benatar M, et al. Long-term safety and efficacy of eculizumab in generalized myasthenia gravis. Muscle Nerve 2019;60:14-24.

40. Meningococcal infection and eculizumab/complement inhibitors [online]. Available at: pnhleeds.co.uk/professionals/meningococcal-infection-and-eculizumab-complement-inhibitors/. Accessed July 10, 2020.

41. Benamu E, Montoya JG. Infections associated with the use of eculizumab: recom mendations for prevention and prophylaxis. Curr Opin Infect Dis 2016;29:319-329.

42. Girgis N, Sultan Y, Frenck RW Jr, El-Gendy A, Farid Z, Mateczun A. Azithromycin compared with rifampin for eradication of nasopharyngeal colonization by Neisseria meningitidis. Pediatr Infect Dis J 1998;17:816-819.

43. Postow MA, Callahan MK, Wolchok JD. Immune checkpoint blockade in cancer therapy. J Clin Oncol 2015;33:1974-1982.

44. Topalian SL. Targeting immune checkpoints in cancer therapy. JAMA 2017;318: 1647-1648.

45. Makarious D, Horwood K, Coward JIG. Myasthenia gravis: an emerging toxicity of immune checkpoint inhibitors. Eur J Cancer 2017;82:128-136.

46. Mohn N, Beutel G, Gutzmer R, Ivanyi P, Satzger I, Skripuletz T. Neurological immune related adverse events associated with nivolumab, ipilimumab, and pembrolizumab therapy-review of the literature and future outlook. J Clin Med 2019;8: 1777.

47. Moreira A, Loquai C, Pfohler C, et al. Myositis and neuromuscular side-effects in duced by immune checkpoint inhibitors. Eur J Cancer 2019;106:12-23.

48. Kao JC, Brickshawana A, Liewluck T. Neuromuscular complications of programmed cell death-1 (PD-1) Inhibitors. Curr Neurol Neurosci Rep 2018;18:63.

49. Suzuki S, Ishikawa N, Konoeda F, et al. Nivolumab-related myasthenia gravis with myositis and myocarditis in Japan. Neurology 2017;89:1127-1134.

50. Dubey D, David WS, Reynolds KL, et al. Severe neurological toxicity of immune checkpoint inhibitors: growing spectrum. Ann Neurol 2020;87:659-669.

51. Safa H, Johnson DH, Trinh VA, et al. Immune checkpoint inhibitor related myasthenia gravis: single center experience and systematic review of the literature. J Immunother Cancer 2019;7:319.

52. Xu M, Nie Y, Yang Y, Lu YT, Su Q. Risk of neurological toxicities following the use of different immune checkpoint inhibitor regimens in solid tumors: a systematic review and meta-analysis. Neurologist 2019;24:75-83.

53. Abdel-Wahab N, Shah M, Lopez-Olivo MA, Suarez-Almazor ME. Use of immune checkpoint Inhibitors in the treatment of patients with cancer and preexisting autoimmune disease. Ann Intern Med 2018;169:133-134

54. Cooper DS, Meriggioli MN, Bonomi PD, Malik R. Severe exacerbation of myasthenia gravis associated with checkpoint inhibitor immunotherapy. J Neuromuscul Dis 2017 4:169-173.

55. Puwanant A, Isfort M, Lacomis D, Zivkovic SA. Clinical spectrum of neuromuscular complications after immune checkpoint inhibition. Neuromuscul Disord 2019;29: $127-133$. 


\section{Neurology}

\section{International Consensus Guidance for Management of Myasthenia Gravis: 2020}

Update

Pushpa Narayanaswami, Donald B. Sanders, Gil Wolfe, et al.

Neurology 2021;96;114-122 Published Online before print November 3, 2020

DOI 10.1212/WNL.0000000000011124

\section{This information is current as of November 3, 2020}

\section{Updated Information \&} Services

References

Citations

Subspecialty Collections

Permissions \& Licensing

Reprints including high resolution figures, can be found at: http://n.neurology.org/content/96/3/114.full

This article cites 53 articles, 10 of which you can access for free at: http://n.neurology.org/content/96/3/114.full\#ref-list-1

This article has been cited by 3 HighWire-hosted articles: http://n.neurology.org/content/96/3/114.full\#\#otherarticles

This article, along with others on similar topics, appears in the following collection(s):

Myasthenia

http://n.neurology.org/cgi/collection/myasthenia

Information about reproducing this article in parts (figures,tables) or in its entirety can be found online at:

http://www.neurology.org/about/about_the_journal\#permissions

Information about ordering reprints can be found online:

http://n.neurology.org/subscribers/advertise

Neurology ${ }^{\circledR}$ is the official journal of the American Academy of Neurology. Published continuously since 1951 , it is now a weekly with 48 issues per year. Copyright Copyright (C) 2020 The Author(s). Published by Wolters Kluwer Health, Inc. on behalf of the American Academy of Neurology.. All rights reserved. Print ISSN: 0028-3878. Online ISSN: 1526-632X.

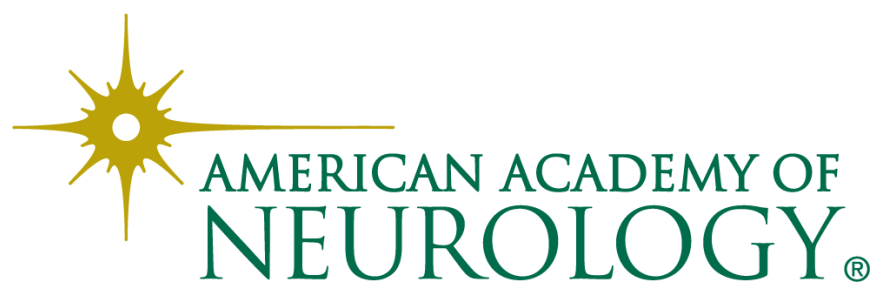

